\title{
Exploration of a New Practical Teaching Mode of Production-learning Combination Based on Internet
}

\author{
Hu Aihua \\ Hebei University of Economic and Business \\ School of information technology \\ Shijiazhuang, Hebei, China
}

\author{
Li Jianke, Yang Yuchi \\ Hebei University of Economic and Business \\ School of information technology \\ Shijiazhuang, Hebei, China
}

\begin{abstract}
In order to adapt to the development of emerging industries, new engineering education has become the development direction of university education. Taking FPGA as an example, this paper relies on integrated online and offline integrated platform of industry and learning to explore the combination of online self-learning based on Internet+ and offline group cooperation learning. The new model of practical teaching can reduce the cost of equipment in the practice teaching of engineering, improves the autonomy of students' practical teaching, breaks away from the limitations of the laboratory, realizes the combination of practical teaching of engineering and the forefront of new industrial development, and cultivates students' learning ability, practical ability, innovation ability and competition and cooperation ability. Through the internalization of knowledge and the development of potential, we attach importance to the important adaptability of science and technology development and social experience to talents.
\end{abstract}

Keywords-Practical teaching; New engineering; Internet+; integration of industry and learning; FPGA

\section{INTRODUCTION}

With the development of Chinese new industry, the demand for knowledge-based, skilled and innovative talents is increasing. With the advancement of society and science and technology, the rapid updating and integration of new knowledge and new technologies requires a large number of new interdisciplinary engineering and technical personnel. In 2017, the Ministry of Education issued the "Guidelines for New Engineering Research and Practice Projects" [1], proposing "the reform and practice of new engineering and multi-disciplinary education mode". The "Industrial and Educational Integration" proposed by the State Council pointed out new education for higher engineering education direction. Emphasizing the cooperation mode of industry and education to cultivate students' engineering practice ability makes the engineering education system at the forefront of the world [2].

In the development process of new industrial technology towards Internet industrialization, industrial intelligence, and industrial integration, artificial intelligence, unmanned control technology and virtual reality technology in the information

Fund Project: Research and Practice Project of Higher Education Teaching Reform in Hebei Province (No.: 0112180133); Teaching Project of Hebei University of Economics and Business (No.: 0130110290). Key Basic Research Project of Hebei Province under Grant No. 16960314D industry are the focus of industrial development in various countries. Aiming at the requirements of economic and social development and enterprise technology innovation, it is an important task for higher education to cultivate applied technical talents with both industry background knowledge and engineering practice ability [3].

In order to meet the needs of the development of the industry, the practical teaching of colleges and universities needs to carry out corresponding reforms. On the basis of increasing the intensity of practical teaching, combined with modern technology, the practical teaching is creatively moved to a more resourceful Internet platform. Taking the practice teaching of FPGA in electronic information engineering as an example, this paper explores a new mode of practical teaching based on Internet cloud platform, reduces the equipment cost of engineering practice teaching, improves the autonomy of students' practical teaching, and breaks away from the limitations of laboratories to realize engineering practice. The combination of teaching and the frontier of new industrial development.

\section{IMPLEMENTATION OF THE CONDITIONS FOR THE PRACTICE TEACHING OF FPGA BASED ON INTERNET+}

\section{A. Implementation of the conditions for the practice teaching of FPGA based on Internet+}

In the past three years, major companies have launched FPGA cloud computing platforms. In September 2014, Altera and Baidu cooperated to use FPGAs in data centers. In November 2015, IBM released FPGA Super Clouds Super Vessel; February 2016, Amazon introduced EC2 F1 (FPGA Acceleration Cloud); in September 2016, Microsoft announced the deployment of 570,000 FPGA servers; in November 2016, Inspur, Intel released the strongest FPGA accelerator card in the US; January 2017, Tencent and Ali FPGA cloud server has been released; in March 2017, Intel released the robot brain of CPU+FPGA; in June 2017, OpenHEC Lab's deep learning FPGA accelerator training camp started [5].

The FPGA cloud platform provides developers with more economical resources, which provides conditions for the development of artificial intelligence and other fields. In order to enable more technicians to join the FPGA development and learning team, a cloud-based online platform has emerged. The 
training laboratory laid the foundation for the emergence of a new model of practical teaching in colleges and universities. In order to cultivate high-quality talents with more innovative ability and competitiveness, higher education institutions should make full use of these resources, make bold attempts on the basis of traditional practice teaching, and promote the reform of practical teaching mode.

\section{B. Formulating practical teaching goals for adapting to new engineering education}

Today, when the new industry is booming, the new information industry demands students not only to learn theoretical knowledge or technology, but also to raise higher requirements for the cultivation of practical ability and innovative ability. In order to improve students' practical ability, the practice teaching reform has never stopped. There has been a series of models from the laboratory to the off-campus training base to the combination of production, study and research, gradually expanding the students' horizons from classrooms and laboratories to enterprises. Expanded to a more comprehensive production and research platform; from textbooks and test boxes to industrial sites, to the Internet platform. The development trend of Internet industrialization, industrial intelligence, and industrial integration makes it possible for students to get in touch with the forefront of technological development as soon as possible, and it is easier for students to establish their own professional plans, stimulate students' interest in learning and initiative, and thus train students. The ability to learn and the ability to recognize and develop to enhance students' sense of innovation and innovation.

At present, the industrial center of artificial intelligence has moved from the early deep learning algorithms and frameworks to the AI hardware platform. The solution includes both dedicated AI chips and FPGAs, and cloud services from all major players are beginning to provide FPGA computing acceleration. FPGA is a very important professional skill course for electronics related majors. In addition to the basic engineering development ideas of students in the undergraduate stage, it is necessary to focus on cultivating the extended technology of the student FPGA to adapt to the application of the new engineering era.

According to the new trend of engineering development under the background of the new industrial revolution, it can be seen that the core competence of the new engineering students has five core competencies, including personal effectiveness, intellectual ability, academic ability, technical ability and social ability, through the cognitive, introspective and interpersonal skills of talents in the new century [4]. Based on the Internet+ based FPGA practice teaching process, it can take into account the cultivation of five core competences of new engineering students. It is the product of technological development in the new industrial era and the way to carry out education reform in accordance with the requirements of social development.

\section{Integrating foundation and cutting-edge practical teaching content}

The OpenHEC platform is based on the training of FPGA engineers and selects knowledge points to create an ecosystem suitable for engineers to grow. Cloud platform-based FPGA engineer development program, including HLS development and Verilog development, from basic knowledge learning to engineering practice, from function statements to module ports, from sequential logic to state machines, from basic knowledge learning to creation of OpenMIPS processors And the migration to the SoC development based on the accelerated core of the RELAX support package, including the comprehensive knowledge and engineering practices required for FPGA programming. Rich knowledge content and flexible platform resources can be freely integrated according to the training objectives.

The leading role of the teacher in practical teaching can also be realized by creating their own learning path. While making full use of the learning knowledge provided on the platform, teachers can use the hardware resources of the cloud platform to create their own practice according to their own teaching priorities. Teaching content and projects to build your own teaching system.

\section{CONSTRUCting a Cloud Platform Practice TEACHING SYSTEM BASED ON THE INTEGRATION OF KNOWLEDGE AND ABILITY}

The FPGA practice teaching mode which based on internet + is similar to the traditional MOOC, but it is different from the traditional MOOC. Because there are real hardware available on the cloud platform, it can be defined as a hardware practice MOOC. It is not simply to move the FPGA experiment to the cloud platform, and the teaching content and teaching methods have been greatly improved. Based on the cloud platform FPGA practice teaching, the platform provides detailed hardware board instructions by allowing students to participate in the online and offline integration of the "Internet + FPGA" industry-study integration FPGA maker ecosystem (for example: Tiger Beetle's OpenHEC FPGA cloud) For the content support package, for beginners and researchers, all online hardware resources can be used directly online [5]. In addition to the basic learning of FPGA, students can also design, develop, and verify online courses, and participate in competitions and participate in enterprise product development This combines the existing laboratory teaching, curriculum design, corporate training, discipline competition and other practical teaching links [6]. This comprehensive practical teaching method can improve the overall quality of students, and thus cultivate outstanding talents of new engineering. The practical teaching system is shown in Fig 1.

The practical teaching method fully considers the students' individualized needs of the knowledge system. The practical teaching can be divided into different stages including basic level, guiding level and competitive level. The different stages 


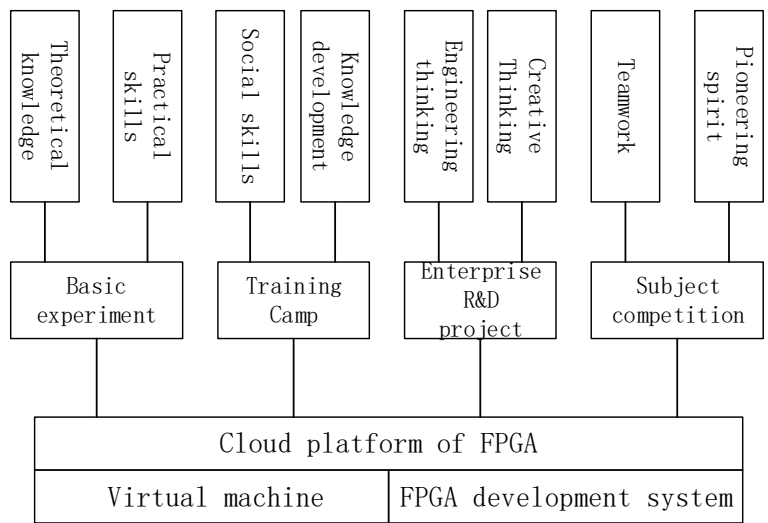

Fig. 1. Cloud platform experimental teaching system

are divided into different stages for students to meet the needs of individualized and diverse practical teaching ability [7], students can arrange their own learning process according to their own situation. Emphasis on the integration and integration of knowledge and capabilities, and the innovation in practice, highlighting the inherent logic of the paradigm shift in the construction of new engineering, and cultivating innovative talents in the new information industry.

\section{A. Explore the online and offline teaching process}

The realization of the teaching objectives requires the subjective initiative of the students. It takes a long time to learn, and the group mode is used for management. During the learning process, the group members communicate with each other, helping each other to complete the learning content, and the phased learning effect. Feedback can help teachers pay attention to students' learning situation, enlighten students' enthusiasm for learning when necessary, and teach students in accordance with their aptitude. Make full use of the information provided by the online cloud platform, and the Q\&A platform has knowledgeable and experienced technicians to provide questions and answers. Discussions by different school students will bring unexpected gains. It will also bring unexpected gains. The schematic diagram of the basic process of teaching is shown in Fig 2.

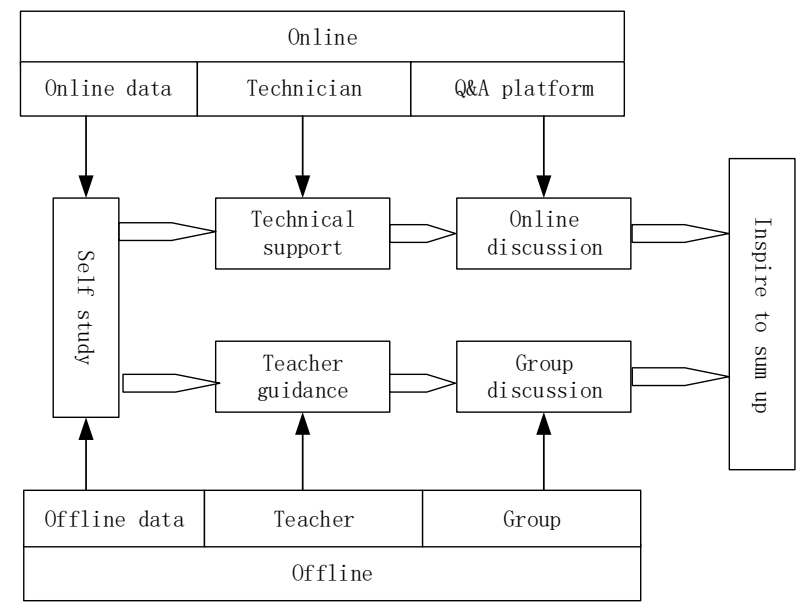

Fig. 2. Practical teaching process of online and offline Industry \& university integration
Based on the cloud platform, the basic experimental part of the practical teaching in the combination of industry and education combines the theoretical ability, the training camp cultivates the ability of students to combine with cutting-edge science, and the enterprise project research and development cultivates students' engineering practice ability. This reflects the logical transformation process initiated by the new engineering discipline from the "technical paradigm" to the "scientific paradigm" to the "engineering paradigm" [8].

\section{B. Study the evaluation criteria for adapting to Internet + practical teaching}

The evaluation method of FPGA practice teaching based on Internet + is different from laboratory classroom teaching. Since the learning mode of students is self-study which supplemented by teacher counseling, the evaluation of teaching quality should focus on the teacher's grasp of teaching attitude, teaching preparation and teaching content. In the details of the teaching process control and teaching effects, the formulation of indicators should focus on the difference between the practice of Internet + and the traditional teaching methods.

According to the teaching objectives mentioned in the first part, various items of teaching effect evaluation [9][10] are given, as shown in Fig 3. Correspondingly, it is necessary to design a student's experimental content record form, an experimental situation questionnaire, participate in a training camp report form, etc. to grasp the student's learning situation and feedback the teaching effect of the student's participation in the online practical teaching process.

From the above, the FPGA practice learning which based on the cloud platform combines the traditional practice teaching content with the advanced technology frontier, expands the time and space of practical teaching, and gives full play to the students' independent learning ability, innovation ability, competition and cooperation ability. It is a new learning model.

\section{SUMMARY}

With the end of Moore's Law, FPGAs will become one of the mainstream computing chips in the future. The students in the school are the mainstream of future development talents, and they need FPGA development platforms that can be used at any time to improve their practical ability. The practice method based on Internet + gives full play to the students' individual autonomy. It is an education concept based on competency. It uses the cloud platform resources and online training camps, enterprise R\&D projects and competitions to cultivate students' four abilities. That is to say, learning ability, practical ability, innovation ability and competition and cooperation ability, through the internalization of knowledge and the development of potential, attach importance to the important adaptability of science and technology development and social experience to talents. Therefore, the promotion of Internet + hardware practice teaching in universities is a good way to improve students' abilities. 


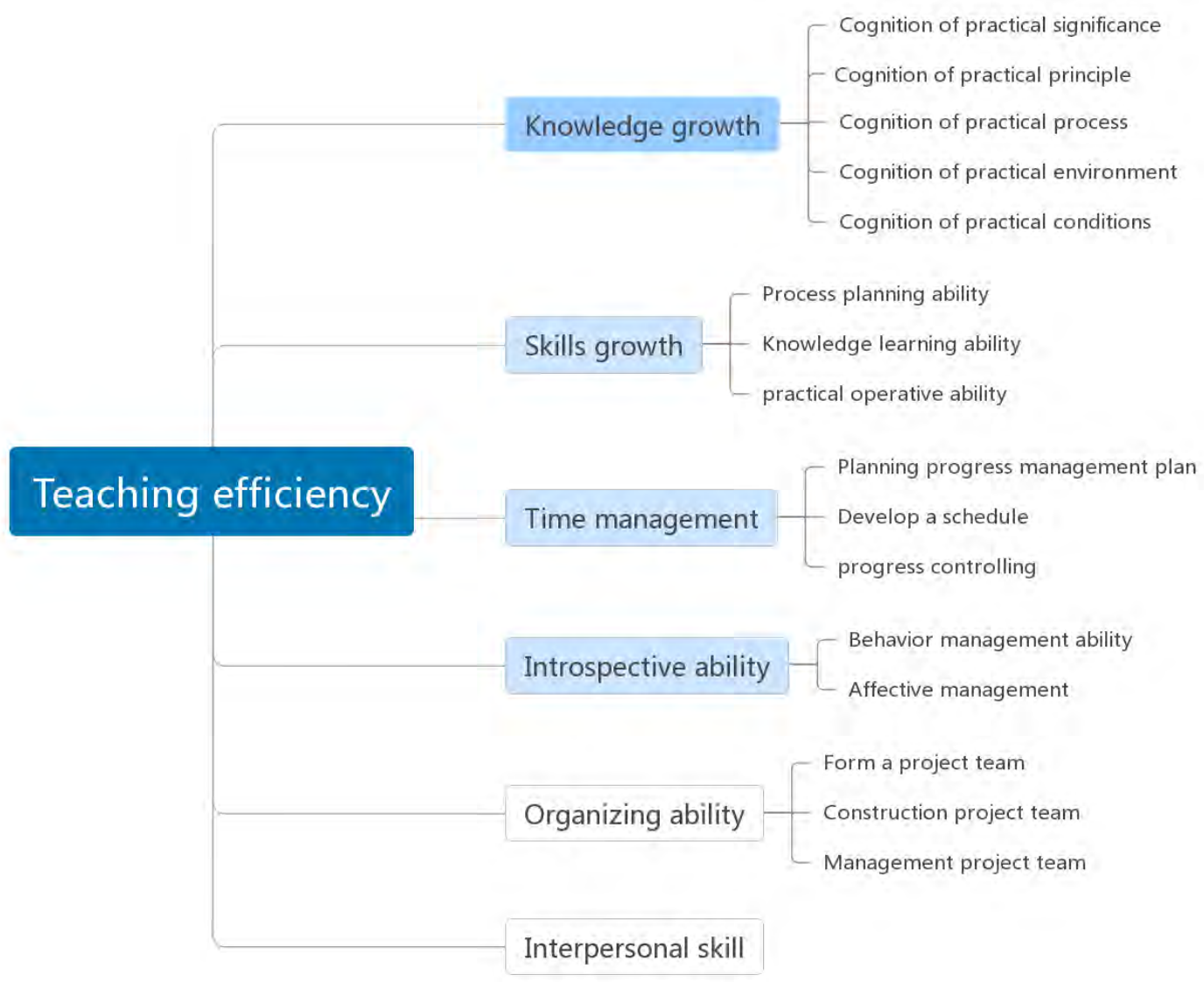

Fig. 3. Teaching effect evaluation

\section{REFERENCES}

[1] Notice of the General Office of the Ministry of Education on recommending new engineering research and practice projects [EB/OL](2017-6-21)[2017-12-1]http://www.moe.edu.cn/srcsite/ A08/s7056/201707/t20170703_308464.html. (In Chinese)

[2] Li Yuqian, Cai Ruilin, Chen Wanming. Construction of Integrated Production and Teaching Integration Platform for New Engineering Based on the Perspective of Incomplete Contract[J]. China Higher Education Research, 2018(03): 38-43. (In Chinese)

[3] Lu Guodong, Li Tuoyu. Thoughts on the Path of New Engineering Construction and Development[J]. Higher Education Research, 2017(03) 20-26. (In Chinese)

[4] Zhou Development, Zeng Yuzhen. Exploration of Core Competence and Teaching Model of New Engineering[J]. Chongqing Higher Education Research, 2017, 5(3): 22-35. (In Chinese)

[5] openHEC - Online and offline integrated production and learning integration maker ecosystem, http://www.iopenhec.com/\#!/app/index. (In Chinese)
[6] Dai Yahong, Li Hong, Yan Yangbo, et al. Reform of the Four-in-one Practical Teaching System of "Study and Practice" under the Background of New Engineering[J]. Laboratory Technology and Management, 2017(12). (In Chinese)

[7] Chen Huasheng. Constructing a practical teaching system: from the perspective of goals, logic and models [J]. Heilongjiang Higher Education Research, 2018 (03): 145-147. (In Chinese)

[8] Gu Juping, Jie Jun, Hua Liang. The Path Choice of Innovative Talents Training in Comprehensive Universities under the Vision of New Engineering[J]. University Teaching in China, 2018(01): 56-60. (In Chinese)

[9] Zhang Lieping, Feng Bing, Li Deming. Construction and Practice of Practice Teaching Quality Monitoring System in Local Undergraduate Universities[J]. Laboratory Technology and Management, 2013(7): 193197. (In Chinese)

[10] Yi Liangting, He Shibin, He Miao. Cognition of Practical Teaching Effect Based on Competency Model and Its Evaluation Path Design[J]. Heilongjiang Higher Education Research, 2018(4). (In Chinese) 